\title{
Patterns of failure in cases of carcinoma of esophagus treated with radical concurrent chemoradiation
}

\author{
Naveen $\mathrm{T}^{1}$, Khaleel $\mathbf{I}^{2}$, Kashyap $\mathrm{L}^{3}$, Goyal $\mathrm{S}^{4}$, Govardhan $\mathrm{HB}^{5}$, Sridhar $\mathrm{P}^{6}$, Pramod KPR ${ }^{7}$, Sarkar $\mathrm{N}^{8}$, Sathish $\mathrm{A}^{9}$ \\ ${ }^{1}$ Dr Naveen T, ${ }^{2}$ Dr Ibrahim Khaleel, ${ }^{3}$ Dr Lalit Kashyap, ${ }^{4}$ Dr Surekha Goyal, ${ }^{5}$ Dr Govardhan HB, ${ }^{6}$ Dr Siddanna P Sridhar, \\ ${ }^{7}$ Dr KPR Pramod, ${ }^{8}$ Dr Nivedita Sarkar, ${ }^{9}$ Dr Sathish A. All affiliated with Department of Radiation Oncology, Kidwai \\ Memorial Institute of Oncology, Bangalore, Karnataka, India
}

Address for Correspondence Dr Govardhan H B, Assistant Professor, Kidwai Memorial Institute of Oncology, Bangalore, Karnataka, India. govardhanhb@gmail.com

\begin{abstract}
Background: Radical chemoradiation has been the main stay of treatment in inoperable cases of carcinoma of thoracic oesophagus. The purpose of the study is to determine the pattern of recurrence after radical concurrent chemoradiation. Materials and Methods: Fifty patients with carcinoma esophagus treated with chemoradiation were taken retrospectively for this study. All the patients were treated with external beam radiation therapy (3DCRT/IMRT) of 54 to $59.4 \mathrm{~Gy}$ with 3 weekly cisplatin $80 \mathrm{mg} / \mathrm{m} 2$ and capicitabine $1250 \mathrm{mg} / \mathrm{m} 2$. All patients were followed with upper GI endoscopy at 3-4 monthly for first 3 years, CECT thorax and abdomen at every 3 month for 1 year then 6 monthly up to 3 year thereafter yearly follow up. Appropriate statistics were used for the analysis. All the patient information was taken out from the case files and by telephonic interview. Results: 50 patients were included in the retrospective analysis. Median age was 54 years. $26(52 \%)$ were males and $24(48 \%)$ were females. Most common tumour histology being squamous cell carcinoma and most common site being the middle 1/3 of esophagus 30/50(60\%). 47/50 (94\%) patients received concurrent chemoradiation with cisplatin with capecitabine and 3/50 (6\%) received induction chemotherapy with cisplatin and 5-FU. Patients were followed up for a period of 8 months to 34 months (median: 21 months). At the time of last follow up in September 2015, 23/50(46\%) patients had local recurrence, 14 (28\%) patients had distant failure and $13(26 \%)$ patients had no evidence of disease at the time of last follow up. With a median follow up of 21 months, mean overall survival for all the patients was 17.5 months. Patients surviving at the end of 1 year were $68 \%$, at 2 years was $36 \%$, and at 3 years was $4.3 \%$. Conclusion: This study concludes that highest incidence of failure and recurrences occur most commonly locally (within the previously irradiated field) even after definitive radical treatment with concurrent chemoradiation. As the local recurrence is more than distant failure we should aim at consolidating the local therapy by dose escalation or alternative radiation therapy.
\end{abstract}

Key words: Esophageal Cancer, Chemoradiation, pattern of failure

\section{Introduction}

Esophageal carcinoma is the eighth most common cancer in the world constituting approximately $6 \%$ of all gastrointestinal malignancies and its incidence is raising annually [1]. Surgery is the primary modality of treatment in localized esophageal cancers but the survival rates with only one modality of treatment is very poor with 3-5 year survival rates being only 5 to $20 \%$ [2-4]. Multimodality approach with surgery and chemoradiation is the standard of care in present day

Manuscript received $3^{\text {rd }}$ April 2016

Reviewed: $14^{\text {th }}$ April 2016

Author Corrected: $26^{\text {th }}$ April 2016

Accepted for Publication $10^{\text {th }}$ May 2016 scenario. Tumours which are locally advanced are inoperable and are taken up for definitive chemoradiation. This combination of chemotherapy and radiation has an additive effect with respect to increasing the disease free survival rates and also the overall survival of inoperable cases of carcinoma esophagus [4-7]. The dose of radiation for radical intent is similar to the dose used for preoperative chemoradiation i.e. 54-60Gy. Use of more sophisticated treatment modalities such as IMRT have aided in dose escalation to the gross tumour volume and at the same time sparing the normal tissues. Several studies have 
attempted to evaluate the pros and cons of doseescalations for esophageal cancer. Even after the use of advanced technologies for the treatment, recurrences are common in these patients. This study is done to know the sites of failure in patients with carcinoma esophagus treated with definitive radical intent by concurrent chemoradiation.

\section{Materials and Methods}

We retrospectively analysed 50 patients of locally advanced carcinoma esophagus who were treated with concurrent in a regional cancer centre between 2011 and 2014.

All patients were treated with conformal radiotherapy. They underwent a planning computerized tomography (CT) and the GTV was contoured based on the CT scans at the time of evaluation and OGD findings. CTV was contoured by extending the margins to $3 \mathrm{~cm}$ in superior and inferior direction and $1 \mathrm{~cm}$ radially. PTV was generated by adding a $0.5 \mathrm{~cm}$ margin to CTV. All organs at risk were contoured i.e. heart, lungs and spinal cord. All patients were prescribed to a dose ranging from 54-59.4Gy at 1.8-2 Gy per fraction along with concurrent weekly cisplatin at $40 \mathrm{mg} / \mathrm{m} 2$ and oral $5-\mathrm{FU}$ in the form of Capecitabine at $1350 \mathrm{mg} / \mathrm{m} 2$ dose. Median overall treatment time for completion of radiation therapy was 48.6 days. Patients were followed up for maximum of 34 months with minimum being 12 months of follow-up.

We assessed the patterns of failure in these patients i.e. local, regional or distant failure based on posttreatment investigations. Barium swallow x-ray and upper gastroduodenoscopy was performed three monthly for the first one year and thereafter six monthly for the next two years. CT scan of thorax and abdomen with IV contrast was done six monthly for three years. Failure is considered if these is any suspicious lesion which is radiologically documented or pathologically proven.

Any failure within the radiation treatment volume or in the regional lymphatics like mediastinal or supraclavicular or abdominal group is considered to be loco-regional failure and recurrence in any other organ or non-regional lymph nodes is considered as distant failure. All failures are included in the analysis regardless of the timing of failure.

\section{Results}

50 patients were included in the retrospective analysis. Median age was 54 years (minimum age 38 years and maximum age 76 years). $26(52 \%)$ were males and 24(48\%) were females. Most common tumour histology being squamous cell carcinoma and most common site being the middle $1 / 3$ of esophagus 30/50(60\%). 47/50 (94\%) patients received concurrent chemoradiation with cisplatin with capecitabine and 3/50 (6\%) received induction chemotherapy with cisplatin and 5-FU.

\begin{tabular}{|l|l|}
\hline Characteristics & Patients \\
\hline Sex & \\
\hline Male & $26(52 \%)$ \\
\hline Female & $24(48 \%)$ \\
\hline Age (yr), Median (range) & $54(38-76)$ \\
\hline Primary tumor location & \\
\hline Upper & $10(20 \%)$ \\
\hline Middle & $26(52 \%)$ \\
\hline Lower & $14(28 \%)$ \\
\hline Histology of primary tumor(SCC) & \\
\hline G1 & $18 \%(36 \%)$ \\
\hline G2 & $26(52 \%)$ \\
\hline G3 & $6(12 \%)$ \\
\hline Technique of treatment & \\
\hline IMRT & $8(16 \%)$ \\
\hline 3DCRT & $42(84 \%)$ \\
\hline Concurrent chemotherapy & \\
\hline weekly Cisplatin + Cepcitabine & $47(94 \%)$ \\
\hline Weekly cisplatin & $3(6 \%)$ \\
\hline
\end{tabular}


Patterns of Failure: Patients were followed up for a period of 8 months to 34 months (median: 21 months) or till death of the patient. At the time of last follow up in September 2015, 23 (46\%) patients had loco-regional failure, 14(28\%) patients had distant failure and $13(26 \%)$ patients had no evidence of disease at the time of last follow up.

\begin{tabular}{|l|l|}
\hline Loco-regional failure & $23(46 \%)$ \\
\hline Distant failure & $14(28 \%)$ \\
\hline No evidence of disease & $13(26 \%)$ \\
\hline
\end{tabular}

Disease Free Survival: With a median follow up of 21 months, median disease free survival was 14.3 months. Disease free survival at 1 year was $26 / 50(52 \%)$, at 2 years was $5 / 13(38 \%)$, at 3 years was $1 / 23(4.3 \%)$.

Overall Survival: With a median follow up of 21 months, median overall survival for all the patients was 17.5 months. Patients surviving at the end of 1 year were $68 \%$, at 2 years was $36 \%$, and at 3 years was $4.3 \%$.

\section{Discussion}

Use of concurrent chemoradiation by radical intent as a standard of care for inoperable cases of carcinoma esophagus has shown poor results [9] in controlling the disease with failure being most commonly occurring at the primary site of the disease. With the advent of advanced technologies for tumour delineation and appropriate treatment delivery, intensification of the local therapy is one of the main aspects of treatment of these tumours [10-12]. Dose escalation at the local site should be considered in treating these patients. This is supported by previous studies demonstrating that for solid tumors, a minimum of $65 \mathrm{~Gy}$ to $70 \mathrm{~Gy}$ would be needed for tumour control [13]. While chemotherapy can help to some degree, it does not change the fact that the dose used for radical intent is not adequate to achieve a high probability for local control.

In the previously noted dose escalation trial RTOG 9405 , dose escalation was thought to be ineffective and highly toxic; most of the patients in that study could not receive even a dose of 50.4 Gy owing to toxicity [14]. Thus, dose escalation should be considered keeping in mind several drawbacks associated with it. Given the proximity of the esophagus to the heart and lung, patients should be planned such that dose to these critical structures lies in the acceptable range. Highdose radiation therapy could increase the risk of esophageal stricture and or perforation, a potentially life-threatening complication [15]. It has also been shown that a simultaneous integrated boost IMRT technique could increase the dose to the primary gross tumor by $28 \%$ while simultaneously achieving reductions in cardiac and pulmonary doses secondary to improved treatment planning techniques.

In summary, we found that local control after definitive chemoradiation therapy for esophageal cancer remains a problem. It is warranted to explore potential ways of improving local control including dose escalation, better techniques of treatment delivery such as IMRT. It seems appropriate to evaluate patient-based risk factors such as tumour status, tumour length, and other biological correlates that seem to predict local versus systemic relapses.

Funding: Nil, Conflict of interest: None initiated. Permission from IRB: Yes

\section{References}

1. Ferlay J, Shin HR, Bray F, Forman D, Mathers C, Parkin DM. Estimates of worldwide burden of cancer in 2008: GLOBOCAN 2008. Int J Cancer. 2010 Dec 15;127(12):2893-917. doi: 10.1002/ijc.25516.

2. Kelsen DP, Winter KA, Gunderson LL, et al. Longterm results of RTOG trial 8911 (USA Intergroup 113): a random assignment trial comparison of chemotherapy followed by surgery compared with surgery alone for esophageal cancer. J Clin Oncol. 2007; 25(24):3719-25.

3. Bosset JF, Gignoux M, Triboulet JP, et al. Chemoradiotherapy followed by surgery compared with surgery alone in squamous-cell cancer of the esophagus. N Engl J Med. 1997; 337(3):161-7.

4. Walsh TN, Noonan N, Hollywood D, Kelly A, Keeling N, Hennessy TP. A comparison of multimodal therapy and surgery for esophageal adenocarcinoma. $\mathrm{N}$ Engl J Med. 1996; 335(7):462- 7.

5. Tepper J, Krasna MJ, Niedzwiecki D, et al. Phase III trial of trimodality therapy with cisplatin, fluorouracil, radiotherapy, and surgery compared with surgery alone for esophageal cancer: CALGB 9781. J Clin Oncol. 2008; 26(7):1086-92. 
6. Forastiere AA. Treatment of locoregional esophageal cancer. Semin Oncol. 1992; 19(4 Suppl 11): 57-63.

7. Herscher LL, Cook JA, Pacelli R, Pass HI, Russo A, Mitchell JB. Principles of chemoradiation: theoretical and practical considerations. Oncology (Williston Park). 1999; 13(10 Suppl 5):11-22.

8. Minsky BD, Pajak TF, Ginsberg RJ, et al. INT 0123 (Radiation Therapy Oncology Group 94-05) phase III trial of combined-modality therapy for esophageal cancer: high-dose versus standarddose radiation therapy. J Clin Oncol. 2002; 20(5):1167-74.

9. Minsky BD, Pajak TF, Ginsberg RJ. INT 0123 (Radiation Therapy Oncology Group 94-05) phase III trial of combined-modality therapy for esophageal cancer: high-dose versus standard-dose radiation therapy. J Clin Oncol. 2002; 20:1167-74.

10. Zhu XR, Sahoo N, Zhang X, et al. Intensity modulated proton therapy treatment planning using single-field optimization: the impact of monitor unit constraints on plan quality. Med Phys. 2010 Mar;37(3):1210-9.

11. Welsh J, Palmer MB, Ajani JA, et al. Esophageal Cancer Dose Escalation using a Simultaneous
Integrated Boost Technique. Int $\mathrm{J}$ Radiat Oncol Biol Phys. 2012 Jan 1;82(1):468-74. doi: 10.1016/ j.ijrobp. 2010.10.023. Epub 2010 Dec 1.

12. Welsh J, Riley B, Palmera $M$, et al. Intensity Modulated Proton Therapy Allows Dose Escalation and Normal-Tissue Sparing in Locally Advanced Distal Esophageal Tumors. Curr Oncol Rep. 2011 Jun; 13(3): 157-167. doi: 10.1007/s11912-011-0158-Z

13. Shukovsky LJ, Fletcher GH. Time-dose and tumor volume relationships in the irradiation of squamous cell carcinoma of the tonsillar fossa. Radiology. 1973; 107(3):621-6.

14. Minsky BD, Pajak TF, Ginsberg RJ. INT 0123 (Radiation Therapy Oncology Group 94-05) phase III trial of combined-modality therapy for esophageal cancer: high-dose versus standard-dose radiation therapy. J Clin Oncol. 2002; 20:1167-74.

15. Marks LB, Zeng J, Light K, Kahn D, Zhou S. 116: Radiation-Induced Esophageal Stricture Following Therapy for Lung Cancer: Its Clinical Course and Analysis Comparing Stricture Length With Isodose Levels. International Journal of Radiation Oncology *Biology*Physics. 2006;66(3, Supplement 1):S66-S67.

\section{How to cite this article?}

Naveen T, Khaleel I, Kashyap L, Goyal S, Govardhan HB, Sridhar P, Pramod KPR, Sarkar N, Sathish A. Patterns of failure in cases of carcinoma of esophagus treated with radical concurrent chemoradiation. Int J Med Res Rev 2016;4(5):747-750.doi: 10.17511/ijmrr.2016.i05.14. 